\title{
MALTESE YOUTH AND THE ENVIRONMENT: A QUALITATIVE STUDY
}

\author{
Mark Christopher Mifsud \\ University of Malta, Malta
}

\begin{abstract}
The present study attempts to highlight the main processes of the acquisition and development of various environmental perspectives and puts forward suggestions on how youth can be better addressed in the light of the research findings. The present paper involved the use of a number of focus groups and a contextual study that examined the development of environmental education on the Maltese islands, considered the main local environmental issues and subsequently analysed the main causes and mechanisms that have shaped the development of the local environment and the Maltese people. An environmental perspectives model was designed employing the technique of graphical display. The research results indicate relatively low positive behaviour towards the environment.
\end{abstract}

Key words: environmental education, attitudes, behaviour, youth

\section{Introduction}

The perception of environmental issues, attitude and knowledge of young people is of great importance due to a number of reasons:

- knowing what students think about the environmental issues will encourage pro-environmental education (Pawlowski, 1996);

- the involvement of youth in decision-making and the implementation of environmental and developmental programmes is critical to the long-term success of Agenda 21 (UNCED, 1992);

- college students are an important segment of society and warrant attention in terms of studying environmental attitudes, as they have been the leading crusaders in the modern environmental movement. For instance, the huge success of Earth Day 1970 in the USA was largely attributed to college students when approximately 1500 colleges participated in the campaign (Harper, as cited in Thapa, 2001);

- according to the Maltese National Youth Policy (Ministry of Education, 2004), the State should follow a policy that helps young people to take an active role in the protection and improvement of the environment for a 
sustainable future and encourage young people to adopt a pro-environmental attitude.

\section{Background to the study - the Maltese context}

\section{The environment}

The Maltese islands are a small archipelago located in the centre of the Mediterranean. The Maltese archipelago comprises three inhabited islands - Malta, Gozo and Comino - with a number of uninhabited smaller islands. The most serious environmental problems arise from the fact that Malta is one of the smallest states in the world and one of the most densely populated. The high population density is augmented further by high tourist arrivals of about 1.2 million yearly (Mallia, Briguglio, Ellul, \& Formosa, 2002). The main environmental issues on the island include waste production and management, reliance on fossil fuels for energy production, high private motor usage and freshwater production requiring a high energy input.

\section{Environmental education development}

Environmental education in Malta started off with environmental NGOs in the 1960's, mainly in response to the major environmental issues on the island. The awareness raising campaign was a very long affair, hindered in its development by a number of factors that lead to the slow growth of environmental education in the islands. These factors include:

- the highly competitive educational system;

- the non-committal policy of the government;

- the colonial mentality.

In the formal education sector one of the major problems is the dominant educational ideology that suppresses creativity and rewards rehearsed words in examinations. Individual teachers who are interested in the environment may attempt to highlight environmental education, but the majority of teachers are hampered with little timetable time and lack of locally produced resources. Some materials currently used in schools were produced for use in other countries, and their transferability in the local context should be cautiously studied.

With regards to the local government, it is apparent that the Maltese government mainly funds projects that have short term goals. Additionally, the lack of a clear national policy on environmental education has resulted in a waste of human resources and the shelving of long-term environmental education initiatives. Due to the fact that Malta was a colony for a long time, a number of anthropologists have indicated that the Maltese people seem to have a problem realising they own the island itself and its environment (Boissevain, 1990). Subsequently, they do not attach much importance to the outside environment. Furthermore, although the Maltese native language is taught and understood 
by everyone, the English language is still considered to be more prestigious. The situation started to improve mainly in response to the requirements imposed on the country by the European Union. The government is now realising that the environmental education is an effective and long-term solution to ensure environmental sustainability. Many government officials speak of their commitment towards sustainability, but their concern is mainly short-term.

\section{Research in the field of youth studies}

There is a considerable body of literature relating to research on the environmental knowledge and attitude. A lot of research has been carried out on primary and secondary school pupils and also on the general population. However, much less emphasis has been placed on the studies that concern post-compulsory education students aged 16-18.

The majority of the studies that focus on students at the secondary school level were primarily quantitative (Barrett \& Kuroda, 2002; Kaplowitz \& Levine, 2005; Makki, AbdEl-Khalick, \& Boujaoude, 2003; Mogenson \& Nielsen, 2001; Tuncer, Ertepinar, Tekkaya, $\&$ Sungur, 2005). There are some qualitative studies (Sivek, 2002). The majority of studies reported a positive attitude towards the environment, except a study by Gambro and Switzky (1996), and a variety of levels of environmental knowledge. Other findings indicate poor knowledge of environmental issues (Kuhlemeier, Huub, \& Nijs, 1999; Gambro \& Switzky, 1999). The majority of the studies did not actually investigate whether youth had taken any actions in relation to the environment.

Few environmental knowledge and attitude studies have been carried out in dense island communities (Volk \& Cheak, 2003; Hsu, 2004; Hsu \& Roth, 1996). These studies are primarily quantitative, except a study by Volk and Cheak (2003).

Hsu and Roth's (1996) study assessed the environmental knowledge and attitudes of a different age group but included a variety of statistical analysis that indicated the significance of certain results. Although the level of environmental knowledge was generally high, relatively negative environmental attitudes were exhibited.

Qualitative studies are few, therefore a potentially fruitful area of research is the use of qualitative methods to carry out research on environmental knowledge, attitudes and actions towards the environment of youth. One way to maximise the potential benefit of these studies is to apply these methods to the local scenario which has been relatively understudied.

\section{Outline of the methodology}

The present study is primarily qualitative, employing hermeneutic/constructivist approaches. It included the use of focus groups and the analysis of the local social, cultural and environmental milieu in which environmental knowledge, attitudes and actions develop. The first part of the study included 'immersion' into various areas of literature that are relevant to the research area to provide a better understanding and provide insights on 
the Maltese situation. The literature review included a number of areas which were then condensed to the following working titles: local environmental issues; development of environmental education; studies of youth and environmental issues.

The results from the issues studied in the three main areas of literature review were used to provide the background for the study. Additionally, the analysis and subsequent synopses of these main issues provided a link between the research questions and the research design. This approach allowed the exploration of Maltese youth in the main postsecondary institutions and was instrumental to shed light on their knowledge, attitudes and actions towards the environment and the processes that lead to the development of such environmental knowledge, attitudes and actions.

\section{The study}

There were four focus groups with a total of 28 youngsters. These were selected through purposeful sampling. More groups seldom produce new insights and generally reach the point of 'saturation' where additional data collection no longer generates new insights (Glaser and Strauss, 1967). The first one was a pilot group and the transcript was examined a number of times by colleagues for feedback.

The main structure of the focus group interviews was as follows:

- What are your concerns about the environment?

- What do you think are the causes of environmental problems?

- How do you think we can improve the Maltese environment?

- What do you do to protect the environment? What actions do you think you can possibly do?

- How do you get informed about the environment? How reliable do you think this information is?

An analysis of the focus groups was carried out during and after the data collection. The 6-8 participants in each focus group volunteered and owing to their student status had certain characteristics in common that relate to the topic of the focus group. The researcher acted as a moderator or an interviewer in all the groups and tried to "create a permissive and nurturing environment that encourages different perceptions and points of view, without pressuring participants to vote, plan or reach consensus' (Krueger, 1994). In all the focus groups, the participants explored the environmental issues facing the Maltese people both from a personal and social perspective. For instance, there was recognition of the potentially high personal cost of acting pro-environmentally. Alternatively, politicians were seen to have short-term interests, not always in line with environmentally responsible, longterm planning.

The qualitative data analysis was based on an adaptation of the approach identified by Vaughn, Schumm and Sinagub (1996) who suggested four processes:

1. identifying the big ideas - the participants' words and ideas and the intensity with which the participants responded provide an initial framework; 
2. unitising the data - identifying units of information from the text that will later become the basis for forming themes;

3. categorising the units - bring together the units of data identified above that are related to the same content;

4. identifying the themes - after considering the big ideas and the categorisation of the units the main themes are identified and refined.

The selection of the 'quotes' to include was informed by a professional judgement of what was important and significant for the context of the study. This, in turn, was based on the considerations of trustworthiness and transparency in qualitative studies, insights gained from the literature review and the existing knowledge of environmental education in Malta and the Maltese environmental-political context rooted in:

- experience in teaching environmental science to college students;

- $\quad$ experience of local and global environmental issues at the Malta Environment and Planning Authority and at the Ministry for Rural Affairs and the Environment;

- $\quad$ experience in the environmental education programmes.

\section{The findings}

No previous focus group study has ever been made on youth and the environment in Malta. The present qualitative study has brought to the surface quite a range of views regarding the Maltese environment. The facilitator asked general questions to stimulate discussion regarding the participants' perceptions of the local environment. With no direct influence from the facilitator, the participants introduced into discussion several broad themes, the main points of which are summarised below.

\section{Trust in the political system and the media}

The participants' trust in the political system was overwhelmingly negative in practically all of the focus groups. The majority of participants sensed that the political parties in Malta are mainly interested in power.

Their only interest is in politics and power.

(Julianne, 2.84)

Most of the participants were very frustrated by the fact that the media in Malta are manipulated, to a great extent, by political parties. 
Maybe the Maltese national television station - the others are just political stations - they just talk about politics - and the news is that either all is good or all is a disaster. I only watch the Maltese national one. It is the best out of the three local ones.

(Samantha, 1.136)

The participants mentioned two main reasons for their belief in the view that the government does not do enough for the environment in terms of laws and law enforcement. Both laws and law enforcement are seen as being one way of how the political party in power can lose votes. The following statements illustrate this premise well, as the participants recount from their own experiences why they perceived the government as dragging its feet on both courses of action.

The problem is that IT is afraid of the people.

(Pierre, 1.19)

Who?

(Moderator, 1.20)

The government - if it enforces something it can negatively influence the voters.

(Pierre, 1.21)

I am not saying that I agree with the government or something - but if it enforces the laws it will work against him. For example, when the labour government enforced the importation laws, everyone turned against it, because that is how illegal objects used to enter.

(Roslyn, 2.86)

Participants also scrutinised the current work carried out by the government with respect to the environment. The general feeling was that of 'apathy' on the governments' part. The perception is that the government is doing very little to protect the environment. Other participants discussed suggestions and explored thoughts on what they really expect from the government. 
The government does not do a lot about the environment. We pay taxes, don't we? Well, actually my mother pays taxes. The government does not do a lot for the environment.

(Oliver, 1.24)

The focus group participants were very positive about the information on the environment provided by schools.

Mainly from schools. And there are some campaigns on television and other campaigns.

(Gianluca, 1.119)

\section{Personal actions}

Many participants reported a variety of different personal actions they perform for the environment. Nonetheless, many of these actions do not actually cost anything, with the exception of one participant who reported the use of biodegradable detergents even though they cost more than traditional detergents. The majority of personal actions reported, involved separating waste into different streams or using reusable items.

I collect all batteries. I collect them in a bag. I do not throw them away.

(Naomi, 1.83)

I use rechargeable batteries whenever it is possible.

(Samantha, 1.84)

When I go shopping, I normally take a cloth bag with me.

(Gianluca, 1.86)

It is interesting to note, however, that, when given a choice, a number of students choose environmentally friendly practices. 
There were offers from the banks regarding the opening of accounts. If you open it with $H S B C$, they plant a tree in your name, but if you open the account with BOV they give you a present. I preferred to open my account with HSBC, so now I have a tree planted in my name.

(Paulette, 2.142)

The influence of parents on youth's personal actions came across as creating a number of occasionally, conflicting concerns. Some parents appear to be providing environmental role models for their children, while other parents perform environmental friendly practices only for their financial payback. Some parents are reported to be totally uninterested in personal actions towards the environment and students report that this attitude may have in fact infiltrated to them as well from their parents.

For me, it is a question of education. Why do I have to switch off? Because I shall have to listen to my mum shouting for an unspecified period of time.

(Loredana, 3.95)

It could be, because my parents also waste a lot. However, now they are putting some breaks on as the bills are really becoming expensive. But they only worry about the money - and they annoy me with their shouting.

(Matthew, 4.66)

\section{Civic responsibility}

The participants in the focus groups were very distressed when discussing civic responsibility. The general perception was that the Maltese public lacks civic responsibility towards the environment. The participants fervently wished for more enforcement and an increase in fines. The participants were positive on instances where people were fined by wardens for environmental offences but generally sceptical of the effectiveness of the enforcement system in its entirety.

The people that dump should be properly fined. There are people who should have been fined one thousand Malta Liri. But this fine is not being really applied by wardens. People contact each other that wardens are coming, and then no one is caught in the act. 
A statement that received approval from a number of participants in the focus group was that financial incentives are being seen as the main driving force behind the environmental responsibility. People are not enticed to behave in a pro-environmental way because of the environment.

I think that a lot of people reduce their use of electricity because it makes financial sense rather because of the environmental benefit.

(Matthew, 4.55)

A number of participants mentioned they do not bother to write letters to politicians or people in authority. Their perception is that these people will not give importance to these letters as they are written by teenagers.

It is a waste of time. They will not give any importance to what we write.

(Larkin, 3.97)

\section{The Maltese people and the local environment}

The participants think that the Maltese people attribute much importance to local politics. One participant pointed out that this tendency seems to have reached 'a way of life' status in the Maltese society. Some local people may be termed political fanatics.

The Maltese are fanatics. About $97 \%$ of all those that could vote actual went out to vote in the last elections. We are on top as one of the countries that has the highest voting turnout. I will try to bring that down. It is senseless, isn't it?

(Matthew, 4.53)

A characteristic which was frequently mentioned by the participants was the perception of the profusion of corruption in all strata of the Maltese society. The participants reported two reasons: politics and the Maltese society, where everyone knows everyone else.

Because there are preferences. Because I know that person, and I know that if I am caught doing something I know I will be freed, because he will not take notice of me.

(John, 4.20)

\section{Education and the role of schools}

The participants described the schooling process as being generally positive in the provision of environmental information, but lacking when it comes to actual or effective 
environmental action. Sometimes the provision of information in the schooling process was considered to be a very important aspect of schooling. In most cases, the participants believed that mainly science teachers provide trustworthy information about the environment.

Mainly the teachers that teach us environmental science and environmental studies. But you do find other teachers that try to raise awareness.

(Gianluca, 1.36)

The participants had challenging experiences that relate to actual pro-environmental actions that are done in schools, mainly because their perception was that it was pointless. Thus, the participants were very reluctant to separate waste as, in the end, the waste bins were still mixed up together by the caretakers and sometimes by the students themselves that did not separate waste.

For instance, in our class we had two different bins: one for paper and one for plastic, however, nobody used them a lot".

(Stephanie, 1.37)

Why, what was the problem?

(Moderator, 1.38)

We were the problem. We still ended up with two dustbins full of mixed rubbish.

(Stephanie, 1.39)

The students are the problem.

(Samantha, 1.40)

We also used to have dustbins in the school. But then, the caretakers used to jumble up everything again notwithstanding our effort. It was no use. The dustbins were in our classes and they use to tell that they keep them separate. But we knew that they (the caretakers) actually mixed everything up. 
The participants also raised questions concerning the ultimate role of local schooling. Their perception was mainly meritocratic, in a sense that schooling is mainly there to provide certification. The participants would hesitate to attend courses if no certificate is gained in the end.

I think that the real problem is the educational system rather than the teacher. The educational system makes you look at something with a certain perspective. Only certificates are important here, learning is not. Why do you think there are all these students here? You really think they come here because they are interested in learning. Most of them come for a certificate.

(Michelle, 4.107)

I am not afraid to say that this is the reason why I come to school. I primarily attend school because of certificates, although I am interested in interesting lessons.

(Matthew, 4.108)

Well, if you do not get certificates, you will end being cut off from the rest.

(Michelle, 4.109)

Several students commented about the usefulness or otherwise of books especially in a school context. One prevalent issue of particular concern was the fact that most books that are currently being used are not locally produced ones but foreign and, therefore, do not focus on the local issues.

I do not know what to say about books. With all respect, they are boring. I like to buy certain books on animals. My mother tells me it's a waste, books on tigers and lions. But the school books, are not nice, I close the science ones as they make me afraid.

(Paulette, 2.168)

I did not buy the school books. I learn a lot from what I see, the environment all around us.

(Terence, 2.169)

I bought them for nothing, because I never open them. 
Why didn't you buy books or use them.

(Moderator, 2.171)

They are on America, not on Malta.

(Emilio, 2.172)

\section{Thoughts about the future}

A number of focus group participants had a number of negative comments about the environmental future of the Maltese islands. They expressed their concern on the way waste is managed and the mentality of people that dump waste in the environment.

The environment will soon be destroyed. We are not taking care of it and are becoming a dump site.

(Tiziana, 3.2)

I agree with Tiziana. It is being destroyed. Everyone is throwing waste - we are destroying everything. No trees are left in the wild, everyone throws old fridges outside.

(Loredana, 3.6)

On the other hand, some participants had a more optimistic outlook and stated that more people are now continuing to study and also mentioned that the fertility level of the Maltese people is decreasing. These factors were seen to contribute towards increased environmental awareness and a stabilisation or decrease in the population.

Malta will eventually move forward, there are many more people continuing to study.

(Gianluca, 1.177)

Overpopulation is a huge problem.

(Stephanie, 1.178) 
Overpopulation will eventually go down. There will be fewer children. We shall emigrate looking for better jobs.

(Gianluca, 1.179)

An overarching response brought up by a number of participants was the importance to increase local environmental awareness. Some participants argued in favour of their possible contribution to increase awareness in the family, at school and at work. Other participants compared Malta to other countries when it comes to dumping. Awareness raising was suggested as a way forward in this regard.

Involve the family. Increase awareness of my friends at work, at school. I am really annoyed when someone throws rubbish on the ground. I really get upset.

(Naomi, 1.115)

In other countries outside of Malta - you do not see paper rubbish on the ground. For example, in New Zealand if you walk barefooted-your feet remain clean.

(Naomi, 1.116)

My mother used to remove her shoes somewhere in the U.K. - about twenty years ago. When I went abroad and came back, I thought that there is a disaster in Malta.

(Samantha, 1.117)

Two other general issues which were identified from the focus groups as requiring much more investment and attention in future were transport and alternative energy. The question of incentives and costs was always at the forefront of the discussions as the participants believed that people, for instance, will not change their habit of predominantly using private transport unless there are incentives or diminished costs involved.

The importance of education in raising environmental awareness was highlighted in the focus groups. In particular, the participants believed in the positive effects of outdoor education on environmental awareness. These findings concur with certain other pieces of work where outdoor experiences have been shown to be important influences on environmental awareness and/or environmental sensitivity (Sivek, 2002).

\section{Environmental perspectives model}

The three distinct axes of young people's perspectives emerged with regard to the island's environmental future: 
- $\quad$ optimism and pessimism (rooted in the perception of society);

- empowerment and helplessness (rooted in the perception of individual);

- ownership and detachment (rooted in the perception of environment).

The majority of perspectives appear to occupy various points created by the intersection of these three continuum lines, around a transition area between the main polar views. The present research does not provide a statistical analysis of the responses in order to pinpoint various locations on the model that would represent groups of youth; rather, the model represents the confines of all the perceptions that were discovered.

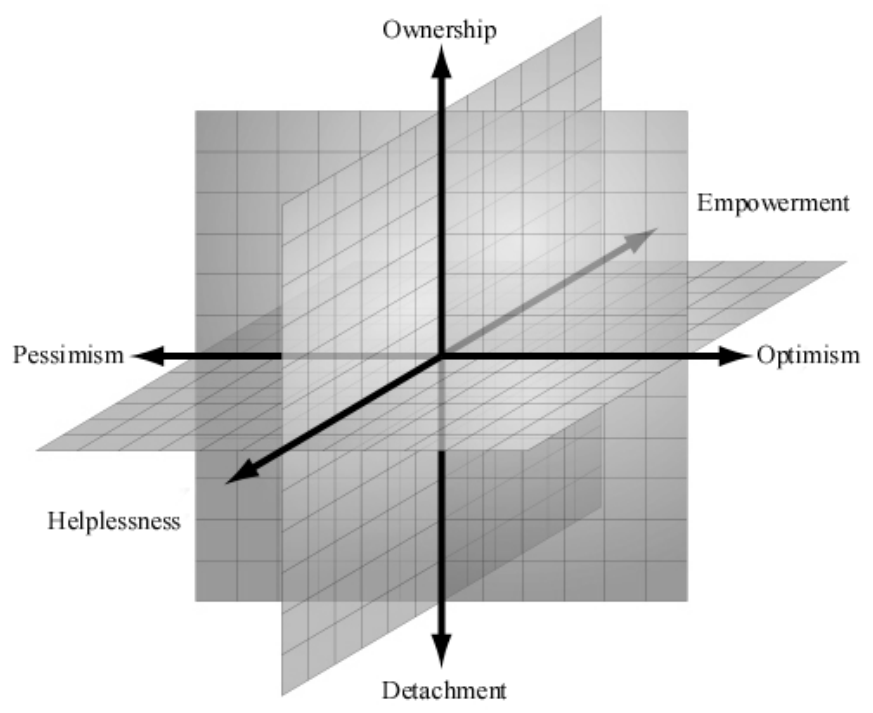

Figure 1. Environmental perspectives model

\section{Optimism and pessimism}

The majority of the participants believe that the Maltese environmental quality has deteriorated over the past years and is in a poor state at the moment. Nonetheless, individuals come to terms with this reality in different ways. The optimists have a positive outlook and argue that more people are now continuing to study, and the fertility level of the Maltese people is decreasing. They understand the limitations of the Maltese people and institutions, but also believe that by collective work and effort our children can and should inherit a better world. Pessimists have a number of negative comments about the environmental future of the Maltese islands. They are concerned about the waste issue and the mentality of local people that dump waste in the environment and who are not really 
interested in the environment. Pessimists view the Maltese people and institutions as being too corrupt with their main interest as economic gain. This continuum line appears to be rooted in the young people's perceptions on the Maltese society itself.

Malta will eventually move forward. Much more people are continuing to study.

(Gianluca, 1.178)

Last year we had an exchange with an English group - and they participated in a workshop on the environment, they discussed and we took a backseat. I did not understand anything. We are a small country when compared to England.

(Stephanie, 1.177)

\section{Empowerment and helplessness}

The participants appear to be actively interested and involved in the environmental activities and have a genuine interest in 'saving the planet'. Some concrete suggestions are put forward, including the possible reclamation of land around the Maltese islands by using demolished waste. This was seen as a possible future scenario, but the students were concerned about the possible impacts on the marine environment. The research participants appear to be active or even pro-active with regard to the events unfolding before them and argue in favour of their own possible contribution to increase environmental awareness in the family, at school and at work in the foreseeable future. On the other hand, helplessness is identified by the participants who view trying to be pro-environmental as a complete waste of time. These participants live by the maxim 'let the future unfold itself then we will see'. They appear to be somewhat passive to the events unfolding before them. In this continuum there is the fatalistic, 'let it be; I cannot do anything about it' approach to the active 'I have to (and can) do something about it'. This continuum line appears to be rooted in the young peoples' perceptions of themselves as individual persons, and 'costs' and 'incentives' appear to play a major part in this continuum.

I do not do anything because it still is futile. Even if you separate waste, the waste collectors will still put all waste in the same collector. It is not worthwhile.

(Larkin, 3.81)

We only use a small amount of water and electricity. All the water we use is nearly entirely coming from the rain because we have a well and we take care of it. We use the water throughout the year, even in summer. 


\section{Ownership and detachment}

The majority of participants believe that the environmental quality has deteriorated over the past years. Nonetheless, some participants appeared to be detached from the local environment, continuously shoving responsibility to the government as if the environment is not their responsibility. Their appreciation of the Maltese environment is very low, and they see it as impoverished when compared to other environments in other geographic regions. They make few connections between their current and future quality of life and the quality of the environment. Other participants showed a higher sense of ownership. They are aware of the uniqueness of our environment and have a good grasp of the complexities and social shades of local environmental issues. They view the environment as a delicate, intricate web. They are aware that their future quality of life depends on the quality of sustaining the environment. This continuum appears to be rooted in the young peoples' perceptions of the local environment itself.

It is mainly the government that should take action. If the government knows that there are these problems, it should churn out some more regulations. And people need to follow the regulations.

(Michelle, 4.18)

If you have furniture that is still usable but you still want to get rid of it, you can send it to Appogg. Appogg is the centre that caters for beaten up women. My father works in the centre, he collects furniture from people and then gives it to the people who are in need and registered with Appogg.

(Sarah, 4.25)

\section{Conclusion and discussion}

The importance of schooling as a provider of good and reliable environmental information has been highlighted in the present study. Nevertheless, more consistency across schools is required, and outdoor education needs to be included in the agenda. In the present study, television is thought of as being the major source of young people's environmental information, and school is the second major provider. The present study also shows convergence with other studies (Pawlowski, 1996; Ivy, Lee, \& Chuan, 1998; Connell, Fien, Lee, Sykes, \& Yencken, 1999; Barrett \& Kuroda, 2002; Said, Yahaya, \& Ahmadun, 2007) where the media were highlighted as the main source of environmental information. In the present study, television has also been afforded a high score for provision of information, but it has a lower rating of reliability. Political interference seems to be a major obstacle.

It is clear that students are more knowledgeable about the global environment than about the local environment. This situation has possibly been brought about by a number of factors, but the main concern is the lack of textbooks on the Maltese environment. 
The importance of factors that influence attitudes has been highlighted in the present study, as these are significantly related to pro-environmental behaviour. The findings on the effect of the local context are supported by Hampel, Holdsworth and Boldero (1996), when they argue that lower socio economic status people would be expected to be more sensitised to the environmental problems and more concerned about them than those in more socially advantaged circumstances. These people have the most dangerous and dirty jobs and more often live in blighted urban areas near busy roads, toxic waste sites, polluting factories, power lines and contaminated water (Hallen, 1994, as cited in Hampel, Holdsworth, \& Boldero, 1996). The importance of parents as environmental role models was highlighted in a study by Sivek (2002), where both the mother and the father achieved high scores as important role models. Moreover, the significance of parents in supporting pro environmental behaviour was emphasised by Connell et al. (1999), where the highest degree of full support for environmental action was from their 'immediate families'.

NGOs, local policy makers and local educators have to take these findings very seriously when devising new environmental education programmes. This is to ensure that such programmes do not just lead to an accumulation of knowledge, but also to improved pro-environmental behaviour. The researchers should start studying the effectiveness or otherwise of such programmes, so that maximum benefit is derived from the limited financial and human resources available.

As a number of environmental problems in Malta are getting worse, the role of young people and future generations in working towards a possible solution becomes more important. In this scenario, schools should be main stakeholders not only in terms of educational policies but also in relation to environmental policies, both at the regional and national level.

Youth have a very positive perception of schools and the information schools supply enjoys a very good reception by youth. Policy makers should attain a primary importance to the implementation of education for sustainable development. Information is properly being supplied by schools, but policy makers need to understand that more knowledge does not necessarily lead to enhanced pro-environmental behaviour. The government should implement education for sustainability in the primary school curriculum. This change needs to be accompanied by the removal of the $11+$ exam which has been identified through the contextual study as the main factor that reduces the possibility of environmental education in the classroom.

At all the primary and secondary school levels, the physical campuses and grounds should be made as sustainable as possible with the use of electricity generation through PV panels and micro wind turbines, waste separation at source, energy conservation with energy saving bulbs, low flush toilets, solar water heaters for water heating, gardens that reflect the Maltese natural environment rather than ornamental and exotic planting and the use of composting heaps.

Most of the suggestions provided above should not be sporadic efforts by individuals or single schools, but should come through a national system that co-ordinates activities and ensures consistency across all schools. In the local scenario, it is imperative that the government leads the way by a project that aims to support activities that can fully engage 
with local youth in order to increase awareness and pro-environmental behaviour. Leading by example is sorely desired by the present youth population.

\section{References:}

Barrett, B. F. D., \& Kuroda, A. (2002). Ecological modernisation, environmental knowledge and societal change: Attitude and behaviour of young people in Japan. International Research in Geographical and Environmental Education, 11(3), 237261.

Boissevain, J. (1990). Why do the Maltese ask so few questions? Education, 3(4), 16-18.

Connell, S., Fien, J., Lee, J., Sykes, H., \& Yencken, D. (1999). 'If it doesn't directly affect you, you don't think about it': A qualitative study of young people's environmental attitudes in two Australian cities. Environmental Education Research, 1, 95-114.

Gambro, J. S., \& Switzky, H. N. (1996). A national survey of high school students' environmental knowledge. Journal of Environmental Education, (27)3, 28-33.

Gambro, J. S., \& Switzky, H. N. (1999). Variables associated with American high school students knowledge of environmental issues related to energy and pollution. Journal of Environmental Education, (30)2, 15-22.

Glaser, B., \& Strauss, A. (1967). The discovery of grounded theory. Chicago, Aldine.

Hampel, B., Holdsworth, R., \& Boldero, J. (1996). The impact of parental work experience and education on environmental knowledge, concern and behaviour among adolescents. Environmental Education Research, (2)3, 287-300.

Hsu, S. J. (2004). The effects of an environmental education program on responsible environmental behaviour and associated environmental literacy variables in Taiwanese college students. Journal of Environmental Education, (35)2, 37-48.

Hsu, S. J., \& Roth, R. E. (1996). An assessment of environmental knowledge and attitudes held by community leaders in the Hualien area of Taiwan. Journal of Environmental Education, (28)1, 25-32.

Ivy, T. G. C., Lee, C. K., \& Chuan, G. K. (1998). A survey of environmental knowledge, attitudes and behaviour of students in Singapore. International Research in Geographical and Environmental Education, (7), 3, 181-202.

Kaplowitz, M. D., \& Levine, R. (2005). How environmental knowledge measures up at a Big Ten University. Environmental Education Research, (11)2, 143-160.

Krueger, R., (1994). Focus groups: A practical guide for applied research. Thousand Oaks, CA: Sage.

Kuhlemeier, H., Huub, V. D. B., \& Nijs, L. (1999). Environmental knowledge, attitudes and behaviour in Dutch secondary education. Journal of Environmental Education, (30)2, 4-15.

Makki, M. H., Abd-El-Khalick, F., \& Boujaoude, S. (2003). Lebanese secondary school students' environmental knowledge and attitudes. Environmental Education Research, (9) $1,21-33$. 
Mallia, A., Briguglio, M., Ellul, A. E., \& Formosa, S, (2002). Physical background, demography, tourism, mineral resources and land use. In State of the Environment Report for Malta (pp. 39-162). Ministry for Home Affairs and the Environment.

Ministry of Education. (2004). National youth policy. Valletta, Malta.

Mogenson, F., \& Nielsen, K., (2001). Students' knowledge about environmental matters and their belief in their own action possibilities. Journal of Environmental Education, 33(1), 33-35.

Pawlowski, A. (1996). Perception of environmental problems by young people in Poland. Environmental Education Research, (2)3, 279-285.

Said, A. M., Yahaya, N., \& Ahmadun, F. (2007). Environmental comprehension and participation of Malaysian secondary school students. Environmental Education Research, 13(1), 7-31.

Sivek, D. J. (2002). Environmental sensitivity among Wisconsin High school students. Environmental Education Research, 8(2), 155-170.

Thapa, B., (2001). Environmental concern: A comparative analysis between students in recreation and Park Management and other departments. Environmental Education Research, 7(1), 39-53.

Tuncer, G., Ertepinar, H., Tekkaya, C., \& Sungur, S., (2005). Environmental attitudes of young people in Turkey: Effects of school type and gender. Environmental Education Research, (11)2, 215-233.

UNCED. (1992). Agenda 21: Programme of action for sustainable development. Rio Declaration on Environment and Development. New York: United Nations.

Vaughn, S., Schumm S. J., \& Sinagub J. (1996). Focus group interviews in education and psychology. London: Sage Publications.

Volk, T. L., \& Cheak, M. J., (2003). The effects of an environmental education program on students, parents, and community. Journal of Environmental Education, (34)4, 12-25.

\section{Correspondence:}

Dr Mark Mifsud, Environmental Science Department, Junior College, University of Malta, Msida MSD 1252, University of Malta, Malta. Fax: +356 21 243036. Email: mark.c.mifsud@um.edu.mt 